\title{
LOWERING BULGARIAN PHYSICIANS' EMIGRATION - POTENTIAL FOR IMMEDIATE ACTION
}

\author{
Stefaniya Bekyarova \\ Department of social medicine and health care organisation, Faculty of Public Health, \\ Medical University of Varna
}

\begin{abstract}
The best human resources for every healthcare system are its own. There should be active polices at all levels of the system for their preservation. Findings of a study of Bulgarian physicians' emigration (1991-2004) to be presented in the paper reveal that low-cost and immediate steps for lowering migration potential could be made by taking advantage of human resources management at level of healthcare facilities. The paper also discusses an attempt to "meet" healthcare managers and human resources professionals and acquaint them with the benefits of their cooperation. We suggest an idea how to effectively develop team work between the two professional groups.
\end{abstract}

Keywords: physicians' migration, lowering migration potential, human resources management

Intensive emigration of physicians is a negative phenomenon for the healthcare system and for society as a whole. Solutions of the professional problems that drive emigration should be actively sought by every healthcare system in order to preserve its own physicians. Having as starting points these two well established principles in the field of human resources for health the current paper has the aim to stimulate and ease the search for solutions of the professional problems that drive Bulgarian physicians' emigration. The aim of the paper is to be achieved, firstly, by selective presentation of the findings of a study explaining Bulgarian physicians' emigration in the period 1991-2004. The focus falls on those nega-

Address for correspondence:

Stefaniya Bekyarova

Department of social medicine and health care organisation, Faculty of Public Health,

Medical University of Varna

e-mail:stef_bekyarova@mu-varna.bg

Received: November 13, 2015

Accepted: December 1, 2015 tive phenomena in the functioning of the physicians' profession that could be solved on level "healthcare organisation" and by utilising the professional approach of human resources management. The reason for the focus selected is that these solutions bring good results at a low cost and their implementation requires a short time. Secondly, a discussion is going to be made of the results of an attempt to "meet" the two professions - physicians and human resources managers - and get them acquainted with the benefits of their cooperation.

\section{BULGARIAN PHYSICIANS' EMIGRATION}

The current paper is based on a study trying to explain Bulgarian physicians' emigration in its depth and integrity. The approach taken in the study contributes to two important developments in migration studies: "acknowledging the non-economic worlds of migration decision-making" (1) and overcoming the "economisation of migration"(1). The thesis of the study is that explanation of the migration decision of Bulgarian physicians should be searched for in the self-identity of the migrant in its human totality and not in one or several of its aspects. Deploying the ad- 
vancements made by Anthony Cohen on the issue of self-identity (2) the study details its thesis in the following way: explanation of the migration decision of Bulgarian physicians should be searched for in their understanding of their selves, of Bulgarian society and of their relationship to it.

In-depth interviewing was chosen as an appropriate qualitative method for realisation of the thesis. This method was complemented by a questionnaire format using the Internet. In this way the study, carried out by the author, gathered data from 37 respondents - 12 interviewees and 25 respondents to the detailed questionnaire. The 37 migrations explored in the study have a time span from 1991 to 2004 . The majority of respondents are in the age group 30-40 years of age. The greatest part of the participants in the study have migrated to old EU member states and the USA.

\section{FINDINGS}

The analysis revealed that migration decisionmaking is rooted in the interaction between the element "migrant's understanding of Bulgarian society" and the other two elements - understanding of one's self and of his/her relation to society - and grows from the serious conflicts that the migrant's self experiences in this interaction.

Here attention is going to be drawn to the following aspects of the desired relation to society (3): giving meaning to one's path of life, the meaning behind the choice of the medical profession, professional aspirations, professional expectations. The focus falls on them because they are of central importance to the physician's profession. The second reason for the selected focus is that the conflicts physicians experience regarding these aspects have the potential to be solved utilising the resources of human resources management. Among its most valuable resources is its analytic approach based on perceptiveness, building a dialogue, responsiveness.

The successful solving of the conflicts would contribute to professional and life satisfaction and would diminish migration potential among physicians.

\section{A. Giving meaning to one's path of life}

This aspect of the desired relation to society is important as it shows how central to the self is the practising of the physician's profession. This is clearly seen in the two forms that this aspect takes among respondents. With very strong presence among study participants is the first form - giving meaning to one's life through realisation of the inner impulse and need to be of help to people. The second form is striving for perfection of one's self. It is understood by some respondents as an integral development of the self while others understand it as a predominant development of one aspect of the self - professional identity. The latter is a prerequisite for overloading professional realisation as the main meaning giving activity in life and for the leading position of professional goals among life goals. In this way a natural consequence of attaining existing professional aims is a crisis of both professional and self-development. The importance of existing formal professional opportunities grows from the expectation and need among study participants professional aims to be formally set within an elaborate system of professional progression and to be demanded.

$B$. The meaning behind the choice of the medical profession.

A common characteristic for all respondents is the presence of their concept for a meaningfully living self in the idea they hold of the medical profession. As a result of this identification the medical profession is perceived as an opportunity to bring to reality the concept of the self, i.e. as an opportunity to be oneself. The identification takes two directions. The leading one is that of putting into the choice of the medical profession the meaning that fills one's path of life. In this sense some of the respondents perceive the practice of the medical profession as an opportunity to be of help to people, while others to develop one's self through enriching one's understanding of human nature and being. The second direction presents the medical profession as an opportunity to fully realise one's inherent intellectual potential and natural aptitude. Attractive features of the medical profession like its prestige, internationalisation, security and good income have come out as secondary in importance as they were mentioned by few respondents and explicitly criticised and rejected by a considerable share of interviewees.

The striving of respondents to render help to others by practising the physician profession is hin- 
dered in reality by the introduction of financial incentives in the doctor - patient relationship. According to respondents pursuing material interests is in conflict with the motivation to cure - compassion. Thus binding economic interests to the medical practice supplants its true driving forces - the needs of the patient and the desire to respond to them.

\section{Professional aspirations.}

All professional aspirations of respondents stem from their desire to be a "good physician". The ethos of the idea of the "good physician" manifests in the high importance attached by almost all respondents to fulfilment and content from the well-performed work, and to professional activity and diligence. A more concrete focus reveals professionalism, humaneness and abiding moral norms as embodying respondents' understanding of the "good physician". From the three elements of the idea of the "good physician" professionalism is essentially important for professional identity. That is why many of the professional aspirations of the respondents ensue from their understanding of professionalism. These include: acquiring and practising quality knowledge from the progress of medical science and for some respondents participating in its generation; knowing and using up-to-date diagnostic and curative technologies. In this sense the respondents aspire to active participation in the international exchange of medical knowledge and its application, i.e. to the practice of medicine at good international level.

A serious barrier to gaining and practising quality knowledge is the strong deterioration of inter-colleague relationships between junior and senior physicians due to the idea that physicians are potential competitors to one another. As a result senior physicians perceive junior physicians as a threat to their professional position which starts a defensive reaction towards them. Thus junior physicians are not given opportunities for demonstrating and proving their capabilities, their high professional successes are left unnoticed, they are not assigned to positions adequate to their professional level and in some cases confront purposefully erected walls that hamper their professional progress.

Professional aspirations face another barrier in reality - the system for professional development and progression offers scarce opportunities. As a conse- quence physicians' striving for professional development and career are canalised in a wrong direction towards the space for advancement opened up by the introduced financial incentives. Success starts to be measured through the number of patients served and the financial benefit brought by them. In this way two parallel and contradictory value systems start to function in the medical profession - one in which the central value is satisfaction from well-performed work and respect as its outer measure and another for which work is mainly a means for making money while a well-done job is measured through material gains. And this situation drags the respondents into a value conflict. A negative form of materialism is one of the most discussed points of conflict. Its manifestations are dishonest practices in the professional and inter-colleague relations planes - irresponsibility, egocentricity, struggle for power at the expense of others, hypocritical and malevolent behaviour. Dishonest practices succeed in supplanting honesty and correctness in inter-colleague relations and in the achievement of professional goals and this presents one of the most painful points of conflict for the respondents. The existence and success of the conflicting value system lowers professional satisfaction, hinders good professional interaction and brings feelings of burden and stress.

\section{Professional expectations}

While professional aspirations present that part of the interaction with society in which the respondents are active, professional expectations put forward the idea of their activity being reflected and coming back to them as sources of satisfaction. At the centre of professional satisfaction stands receiving positive feedback from patients with regards to achieved diagnostic or treatment results. Its contribution to professional satisfaction is first in significance and almost beyond comparison with that of others. It is followed by remuneration in its multiple dimensions - expression of the positive feedback from employer and society, i.e. their appreciation of physicians' work; means for meeting one's own and family vital needs and for maintaining good professional level. Another important expectation is professional development and progression to be based on knowledge, skills and capabilities. 
The received remuneration should correspond adequately to the level of qualification and intensity of labour and to growing responsibilities. It should also allow for investment in professional development.

The expectation that professional development and progression should be based on knowledge, skills and capabilities also collides with reality. In this respect what respondents find in reality is "bureaucracy", "corruption", "cronyism" which are incompatible with high levels of professionalism. The values that regulate access to professional resources which are also the values of respondents, are challenged by new and negative ones. Thus professional life is regulated by different and contradictory values which leads to confusion and unpredictability in achieving goals.

The alleviation of all the negative phenomena presented above falls within the competences of human resources management. This fact inspired the idea to "meet" the two professions - physicians and human resources managers - and get them acquainted with the benefits of their cooperation. The meeting took the form of a round table entitled "Emigration of Bulgarian physicians and management of human resources - interconnections and practical solutions" (The round table was organised by Medical University - Varna, the non-profit organisation "Public Health - 99" and association "Centre for Demographic Research and Training". The event took place on the $16^{\text {th }}$ of March 2012 in Varna. Invitations were sent to all interested parties in the country).

The central figures in the event were managers of healthcare facilities and representatives of the Bulgarian Association of Human Resources Management. The discussion between them was facilitated by researchers in public health, human resources for health and demography.

All participants were acquainted in advance with the results of an analysis of a number of research and international political documents on the issues of physicians' migration and human resources management (HRM). A central conclusion of the analysis was that lowering physicians' emigration requires strong competences in human resources management at all levels of the healthcare system - central, local and especially at level "healthcare facility"(4). In these documents recommendations are made to attract HR-professionals in the healthcare facility management team and change human resources administration with human resources management. In order to overcome the inertia of the "status quo" it is advised to establish departments for human resources management, to staff them with highly competent professionals and with dedicated and persistent leaders and to empower them with the necessary resources to exert influence.

The discussion at the event revealed that healthcare managers are inclined to think of all problems as inherent to the system and requiring greater changes and reform to be solved. HR-professionals encouraged the perspective of thinking also on a small scale and searching for small scale solutions. The discussion of small scale problems was not easy and a barrier was constantly felt. HR-professionals were felt as intruders on foreign territory searching for a new market niche. As a result after the event strong cooperation was established between managers and researchers while HR-professionals remained outsiders.

In order to overcome such development and encourage cooperation with HR-professionals a multisite pilot demonstration project should be carried out at different healthcare facilities with independent financing and leadership - by a research institution. The aim of the project should be thorough analysis of HR-problems, search for solutions and their implementation. The project should demonstrate not only how definite solutions are effective but also how beneficial cooperation with HR-professionals might be. That is why the project activity should be a team work of healthcare managers, HR-professionals, physicians and researchers within a definite healthcare facility.

The analysis of HR-problems might bring out not only small scale problems but also flaws in the functioning of the system at higher levels. They should also be a matter of discussion within the project and suggestions for change of system regulations should be motivated and demanded.

The round table revealed that the emigration of Bulgarian physicians should be "de-economised". The idea that it is chiefly motivated by search for better remuneration was held by almost all participants in the event - HR-professionals, healthcare manag- 
ers, representatives of healthcare administration. Even journalists covering the event made mistakes in their reports that proved the one-sided economised perception of physicians' emigration - the idea that physicians in Europe would be satisfied by a remuneration that is "2-3 times the average salary in the respective country" was cited as "2-3 times their current remuneration" which magnifies the role of money.

The economised perception of migration makes us blind for all other ways in which we can contribute to physicians' professional satisfaction and correspondingly to lowering emigration. Among the low cost and immediately available solutions for the problems that drive migration are those that might be generated in cooperation with human resources management.

\section{REFERENCES}

1. Halfacree K. A utopian imagination in migration's terra incognita? acknowledging the non-economic worlds of migration decision-making. Population, Space and Place. 2004; 10: 239-253.

2. Cohen A. Self Consciousness. An Alternative Anthropology of Identity. London: Routledge; 1994.

3. Bekyarova S. The Concept of the Self in Explaining Post-1989 Bulgarian Physicians' Emigra-

tion. Journal of Identity and Migration Studies. 2011;5(2):20-42.

4. Working materials, Round table "Emigration of Bulgarian physicians and management of human resources - interconnections and practical solutions", Varna, 16 March 2012. Unpublished. 